\title{
Integration of Petrophysical Analysis and Elastic Log Properties as an Input to Optimize the Development Wells Target in Unique Globigerina Limestone Gas Reservoir in Madura Strait
}

\author{
Hendra Himawan*, Indra Sumantri, Okky Yuditya Pahlevi \\ Husky-CNOOC Madura Limited, Indonesia Stock Exchange Building Tower 1 \\ Jend. Sudirman St., Kav 52 Jakarta 12190, Indonesia \\ *E-mail: hendra_himawan@hcml.co.id
}

Article received: 8 July 2021, revised: 10 July 2021, accepted: 30 August 2021

DOI: $10.51835 /$ iagij.2021.1.2.31

\begin{abstract}
The Madura Strait PSC is located in the southern part of North East Java Basin with biogenic gas from Globigerina limestone Pliocene Mundu and Selorejo sequence as main target. At early stage of field development, understanding and knowledge about petrophysical and elastic properties of reservoir rock quality is required and very important. The petrophysical analysis provide properties such as clay volume, porosity, permeability, water saturation and mineral volume to separate reservoir and non-reservoir zone. The elastic rock properties such as acoustic impedance (AI), shear impedance (SI), velocity ratio $(\mathrm{Vp} / \mathrm{Vs})$, and Poisson's ratio $(\sigma)$ were generated to identify clay zone, gas and non-gas also focused to distinguish reservoir rock quality inside gas zone as an effective reservoir characterization. This research is done by utilize core data, quad combo logs from eleven wells and shear velocity from eight wells. The purpose of this research is to optimize development well target in Globigerina limestone gas reservoir, which have good to best reservoir rock quality shown with high porosity and permeability, low clay volume and water saturation. Results from this research indicate that lime mud matrix have significant impact in the reservoir rock quality. Meanwhile, gas saturation can affect the elastic properties due to this high gas saturation can decrease compressional velocity ( $\mathrm{Vp}$ ) value. Finally, the integration of petrophysical result and combination of elastic properties implementation can help in distinguishing the best reservoir rock quality, which contains gas that should be penetrated by the development wells.
\end{abstract}

Keywords: Globigerina Limestone, petrophysical analysis, elastic properties, reservoir quality

\section{INTRODUCTION}

Reservoir characterization is closely related to the understanding of both vertical and lateral reservoir heterogeneity distribution. Understanding in the vertical heterogeneity of reservoir has always been crucial in reservoir characterization. A successful reservoir characterization starts with petrophysical evaluation. Petrophysics combines wireline logging, core, mudlog, and other disparate data sources for evaluating, predicting, and establishing formation lithology, clay volume, porosity, permeability and water saturation [1].
Wireline logging is a study of acquiring physical properties of rocks during or after drilling of a well. Standard wireline log that usually acquired consist of gamma ray (GR), resistivity (micro, shallow and deep), neutron, density $(\rho)$, compressional and shear wave velocities (Vp and Vs). Density, Vp and Vs are mainly related to the elastic parameter which are controlled by the solid component (mineral composition, compaction, clay content, porosity and pore geometry) and also the contained fluid (oil, gas, free water, bound water, and saturation) [2]. Among the various factor affecting velocity, porosity and 
hydrocarbon saturation has dominant control. Higher porosity and hydrocarbon saturation leads to lower bulk density, lower rock rigidity and incompressibility, and accordingly, lower Vp and Vs [3].

This research focusses on elastic properties analysis inside gas bearing interval that is used to optimize development well target that should be penetrated by development wells. The appropriate cluster of elastic properties can distinguish the best reservoir quality, which have high porosity and permeability, low clay content, and low water saturation. This can be as an input to geophysicist because $\rho, \mathrm{Vp}, \mathrm{Vs}$ and elastic parameter are so important. This also can be input for geologist when building a static model. These parameters are key to understand the lateral heterogeneity, reservoir quality distribution and generate the geobody of sweet spot.

\section{REGIONAL GEOLOGY}

The Madura Strait PSC is located in the southern part of North East Java Basin. Major plate movements are responsible for much of the structural development with local stratigraphy and faulting in the sub-basins affected by change in sea level, local structuring and plate interactions. The tectonostratigraphy megasequences of this area divided into three main events, Late Cretaceous, Paleogene and Neogene-present [4]. This paper focus on Neogene-present, due to one of the most widely spread reservoirs coming from Mundu - Selorejo sequences which exist on Neogene-present event as shown in Figure 1.

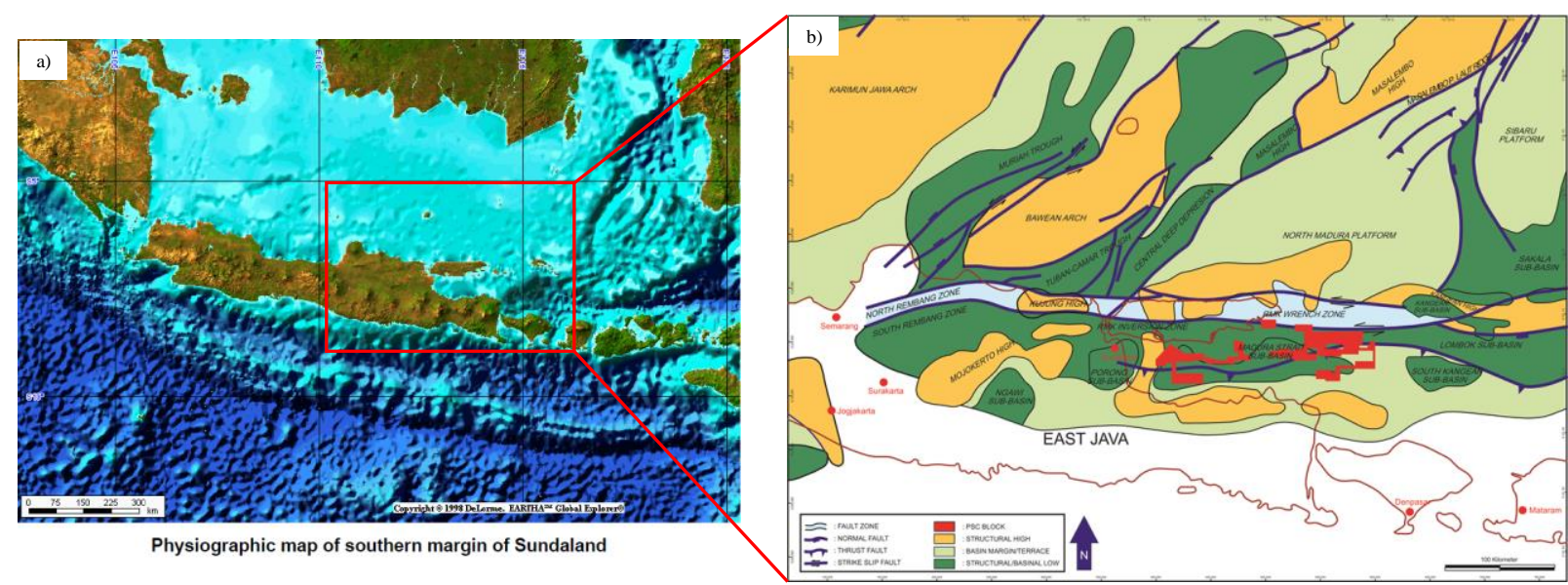

Figure 1. a) Location of Study Area (modified from [4]). b) Regional Geology of Madura strait PSC (modified from $[5])$.

Regionally, the main reservoir target for Pliocene play is the Mundu-Selorejo Sequence. The Mundu Sequence comprises bioclastics grainstones, packstones and wackestone. The sequence is deposited at upper part of Late Miocene to Early Pliocene with the T50 at the top of the sequence as sequence boundary between Mundu and Selorejo Sequence. Meanwhile, within the
Mundu Sequence there is T40A sequence boundary which recognized by nano fossil zonation. The Selorejo Sequence represents a distinct stratigraphic unit distinguished from the underlying Mundu Sequence both on age and on the presence of a significant structural event at end of the Mundu times. In general, the grainstones may be less argillaceous. It is deposited at Middle Pliocene to Late Pliocene 
with T60 sequence boundary at the top of the sequence. This sequence boundary distinguished the Lidah Pleistocene Sequence with the Selorejo Pliocene Sequence. Globigerina limestone terminology that is usually used comprises both the Mundu and Selorejo Sequences [6].

Based on gas geochemistry study, the genetic type of natural gas has been identified in the area is biogenic gas which contain methane more than $96 \%$. The biogenic gas was sourced by the Miocene to Pleistocene Claystone or fine grained which interbedded with reservoir. The Globigerina limestone consists of bioclastic facies limestone, characterized by the abundance of Globigerina foraminifera. Major porosity types encountered in this sequence are intra-particle porosity within foraminifera shell and interparticle porosity (between foraminifera). The pelagic shales of the Lidah Sequence act as an effective regional seal for Mundu - Selorejo
Sequence play. The hydrocarbon charge in the area through methanogenic process was highest in Late Miocene to present with claystone marine shelfal environment (mid outer neritic). Migration is believed comes from Early-Late Pliocene reservoir. Biogenic gas generation and migration is interpreted as a constant process, taking place from the time of deposition continuously in Early Pliocene. Its process will stop until source material exhausted or the aerobic methanogenesis temperature threshold $\left(75-80^{\circ} \mathrm{C}\right)$ exceeded or the burial depth reached approximately 3,000 feet. The biogenic gas interpreted migrated laterally through carrier beds from surrounding area which has sufficient TOC $(>0.5 \%)$, might be intra-shale or siltstone of Early-Late Pliocene sediment, charging the reservoir which is believed relatively close to the trapping structure. Detail petroleum system is shown in Figure 2.

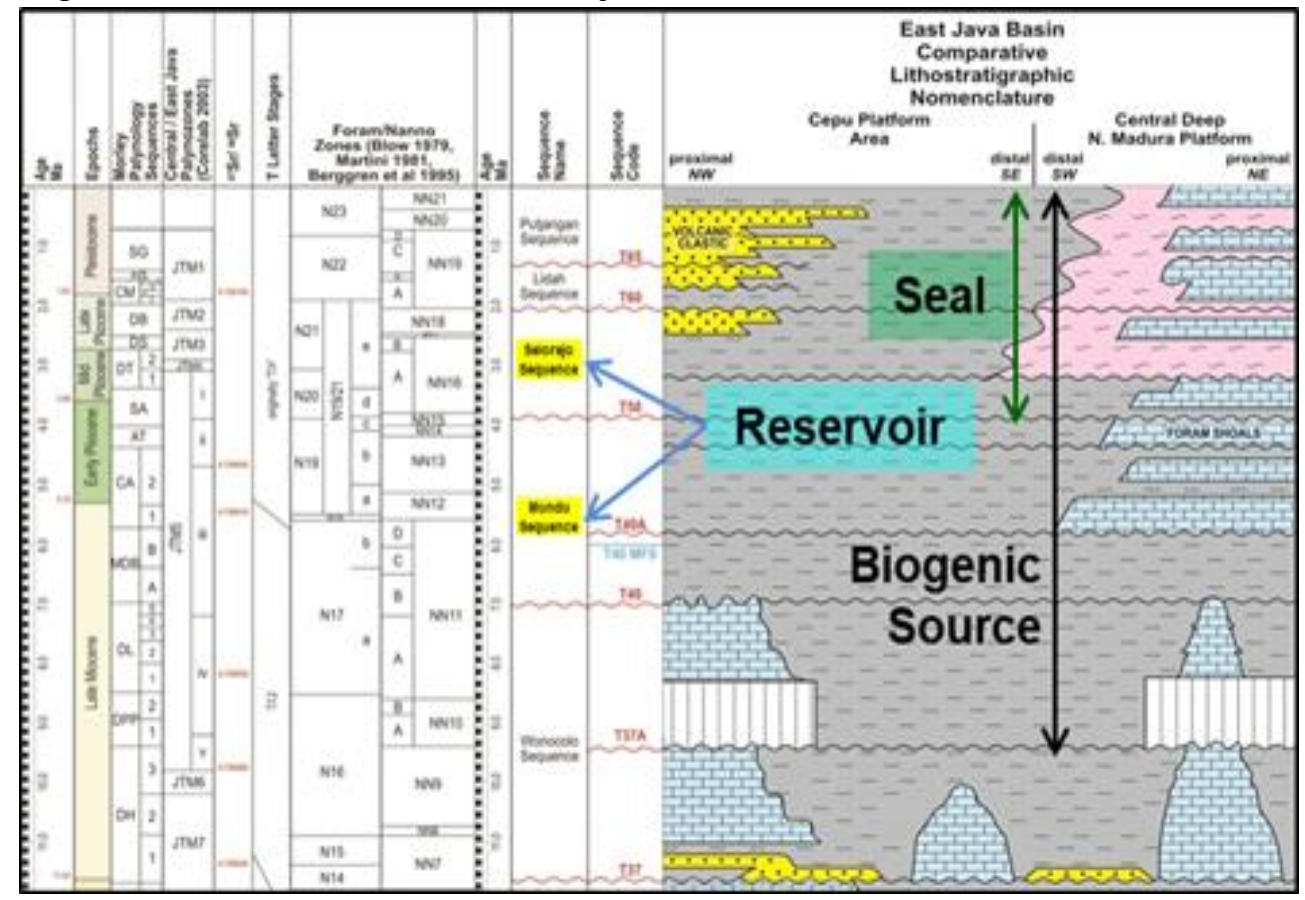

Figure 2. Petroleum System in Madura Strait PSC [7].

\section{DATA AND METHOD}

The data availability for this study consists of mud logs, wireline logs, and core data coming from wells that drilled targeting Globigerina limestone. Eight wells (AX-1, AC-1, BF-1, BH-1, DK-1, DA-1, DA-2st, and 
DA-4) successfully found gas, two wells dry (AX-3 and DA-3) and one well inconclusive (BJ-1). All of the wells acquired wireline logs, which consist of gamma ray, resistivity, neutron, bulk density, Vp and Vs (eight wells) as shown in Figure 3.

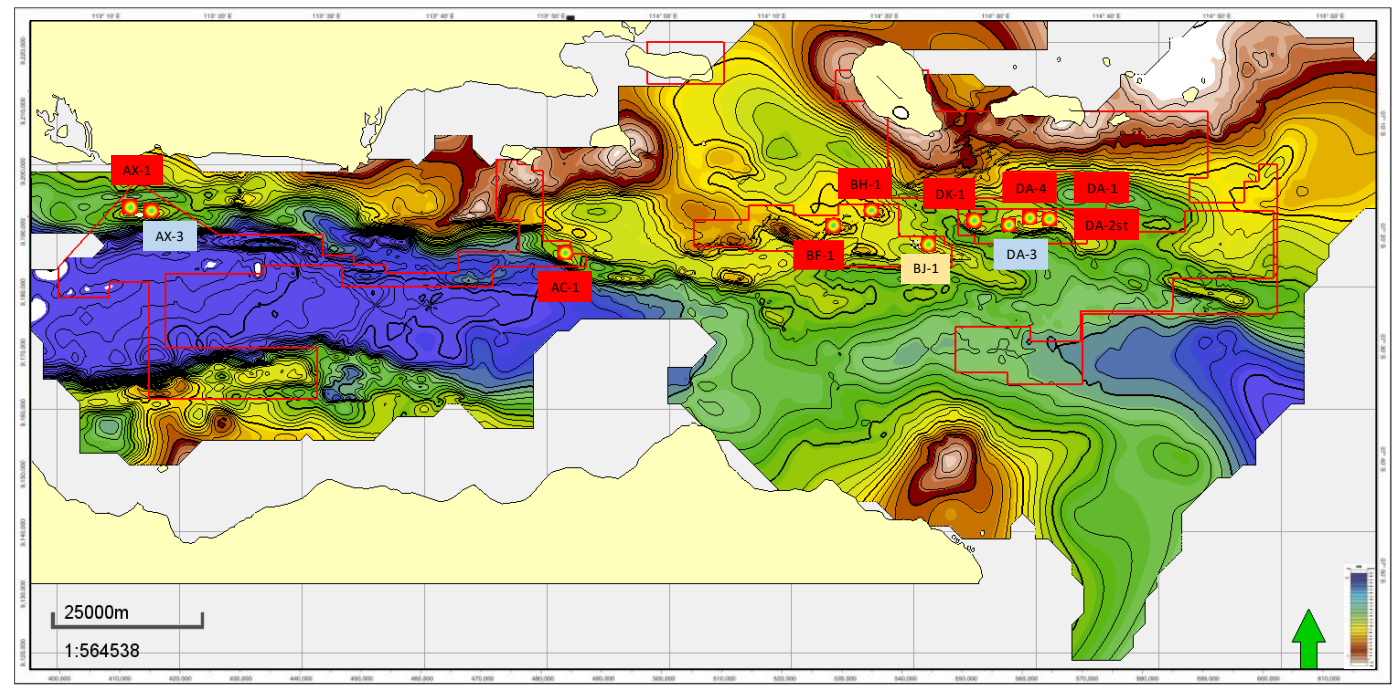

Figure 3. Wells Location Overlay with Top T60 Depth Structure Map

Core data sets of ten wells (except DA2st) from laboratory results include vertical and horizontal permeability, porosity, grain density, petrography (SEM, XRD and Thin Section), formation resistivity, and capillary pressure. Core permeability analysis used in this study refer to horizontal permeability values. Selection of routine core and petrography samples were taken carefully to capture rock and pore type variation in the cores in order to identify reservoir facies and genetic pore types from various positions. Various reservoir quality can be identified using porosity-permeability cross plots to create relationship and predict permeability.

Core data is used to define lithofacies based on lithology, texture (grain size and sorting), and sedimentary structures using the traditional Dunham classification, which emphasizes depositional texture: grain supported versus mud supported. Based on Dunham's classification, the carbonate rock has more diffused clouds which indicating to other major factors as permeability control.
High porosity in carbonates can be observed that does not always give rise to high permeability. However, the clusters of points, which represent carbonate classification are not completely separated from one another.

\section{Petrophysical Analysis}

Petrophysical analysis begins with the data inventory and understand about the geological concept as the foundation for petrophysical analysis. Data quality control includes remove tail, depth matching, log patching, merging, depth shifting, and pseudo log. Petrophysical analysis main objectives are to transform well logs information into reservoir properties such as mineral volumes and fluid contents in the invaded and uninvaded zones. Clay volume is the first step to be estimated using a combination of gamma ray and neutron-density logs. Complex lithology method has been used for analysis of minerals, porosity and water saturation. Neutron-density log use to estimate porosity and deep resistivity log for water saturation. 
Analysis of petrophysics applied appropriate petrophysical parameters and formulas for clastic carbonates and validated with core data.

\section{Volume of Clay}

Clay volume $(\mathrm{Vcl})$ was calculated from combination of gamma ray log and neutrondensity log. When using GR $\log$, it needs to check variable potassium (K) radioactivity high readings. The effect of Uranium to the GR $\log$ was eliminated before it used in computation to minimize gross radioactivity [8]. The neutron $\operatorname{logs}$ can be problematic, hence different tool sizes and vintages are unique depending on differences in the applied environmental corrections and clay type responses. A combination of GR and neutron- density log response was used to calculate clay volume. GR $\log$ was primary $\log$ used to compute the volume of clay using Lorionov Tertiary Rock equation as follows:

$$
V \operatorname{clGr}=0.08336 \times\left(2^{3.7 x Z}-1\right)
$$

where $\mathrm{Z}$ is VclGR linear

$$
V c l G r=\frac{\text { Gr-GrClean }}{\text { GrClay-GrClean }}
$$

Neutron-Density log separation was used to determine clean-clay baseline to which the end values for clean GR and clay GR were determined. The clay volume of densityneutron (VclND) equation as follows:

$$
V c l N D=\frac{(\text { DenCl2-DenCl1 }) *(\text { Neu }- \text { NeuCl1 })-(\text { Den }- \text { DenCl1 }) *(\text { NeuCl2 }- \text { NeuCl1 })}{(\text { DenCl2-DenCl1 }) *(\text { NeuCl }- \text { NeuCl1 })-(\text { DenCl-DenCl1 }) *(\text { NeuCl2 }- \text { NeuCl1 })}
$$

The final calculated clay volume from well logs was validated with total clay from XRD.

\section{Porosity}

Porosity is a fundamental measure of the storage capacity of a rock, whereas both bulk density and porosity are often related to the strength of rock material. Porosity logs that available in all wells are density, neutron, and sonic log. Total porosity was computed using a combination of neutron-density logs as the principal determinant [9]. The bulk density is controlled by the grains and pores and thus reflects the compactness and cementation of the rock, which will affect its overall petrophysical and elastic properties. Below is the equation for density porosity (DPHI) calculation:

$$
\Phi=\frac{\text { Rhoma }- \text { Rhob }}{\text { Rhoma-Rhofluid }}
$$

The neutron log already in limestone porosity units (NPHI) and then manually defines the log input and type of neutron tool environmental corrections. Total porosity is calculated using the following equation:

$$
P H I T=\left[\left(D P H I^{2}+N P H I^{2}\right) / 2\right]^{1 / 2}
$$

Effective porosity is calculated from the combination of neutron-density logs or total porosity with correction for clay content as follows:

$$
P H I E=P H I T-(V c l * P H I T c l)
$$

The calculated porosity log was validated with core porosity at NOB condition.

\section{Permeability Prediction}

Reservoir quality can be identified using porosity-permeability cross plots to create relationship and permeability transform. From the porosity-permeability cross plots, the distribution of porosity and permeability among ten wells are very scattered. The 
clusters of points, which represent carbonate facies based on Dunham classification for each reservoir, are not distinct from each other as shown in Figure 4. The poor poro-perm relationship is common in carbonate rocks implying that porosity is not the only parameter affecting permeability. In other words, the good poro-perm relationship is influenced by lithofacies, facies deposition and diagenesis showed by grain size distribution, texture, roundness, pore type, pore geometry, pore throat size, cement, mineral composition, and connectivity [10]. Therefore, the detail permeability transform should be determined through hydraulic flow unit (HFU).
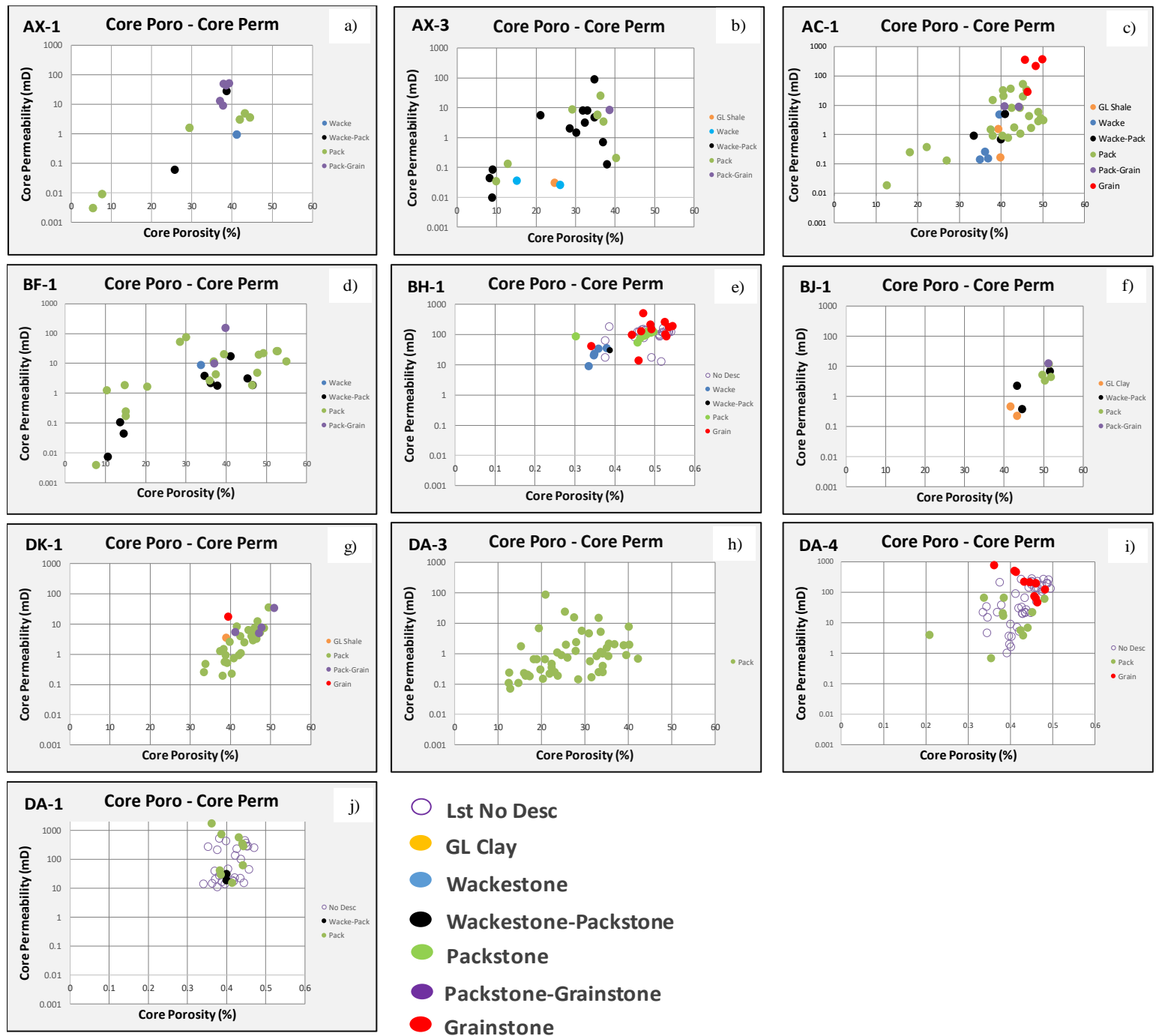

Figure 4. Core Porosity vs Core Permeability cross-plot Color Coded by lithofacies. a) AX-1 well. b) AX-3 well. c) AC-1 well. d) BF-1 well. e) BH-1 well. f) BJ-1 well. g) DK-1 well. h) DA-3 well. i) DA-4 well. j) DA-1 well

HFU's analysis based on indicator of flow zone which reflect to rock quality that influenced by the mineralogical composition and texture of lithology. HFU provide the basic input for the generation of different lithology classes with integration from core description, core porosity, core permeability, petrography (lithofacies, SEM, XRD and Thin Section), mineralogy, relative permeability and capillary pressure. HFU analysis technique has been 
introduced by calculating of flow zone indicator (FZI) from pore volume to solid volume ratio $(\Phi \mathrm{z})$ and reservoir quality index (RQI) [11]. From FZI values, samples can be classified into different HFUs. Samples with similar FZI value will have same HFU. Each HFU on a log-log cross plot between RQI vs normalized porosity index will yield a straight line with a specific unit slope. The intercept of each unit slope with $\Phi z=1$, designated as FZI is a unique number for each HFU. Data points that plot along a constant FZI exhibit similar flow quality across a wide range of pore-perm values as shown in Figure 5. Thus, these ratio lines can be used as a scale to evaluate and rank reservoir quality. The calculated permeability $\log$ was validated with core permeability at NOB condition and Klinkenberg effect.
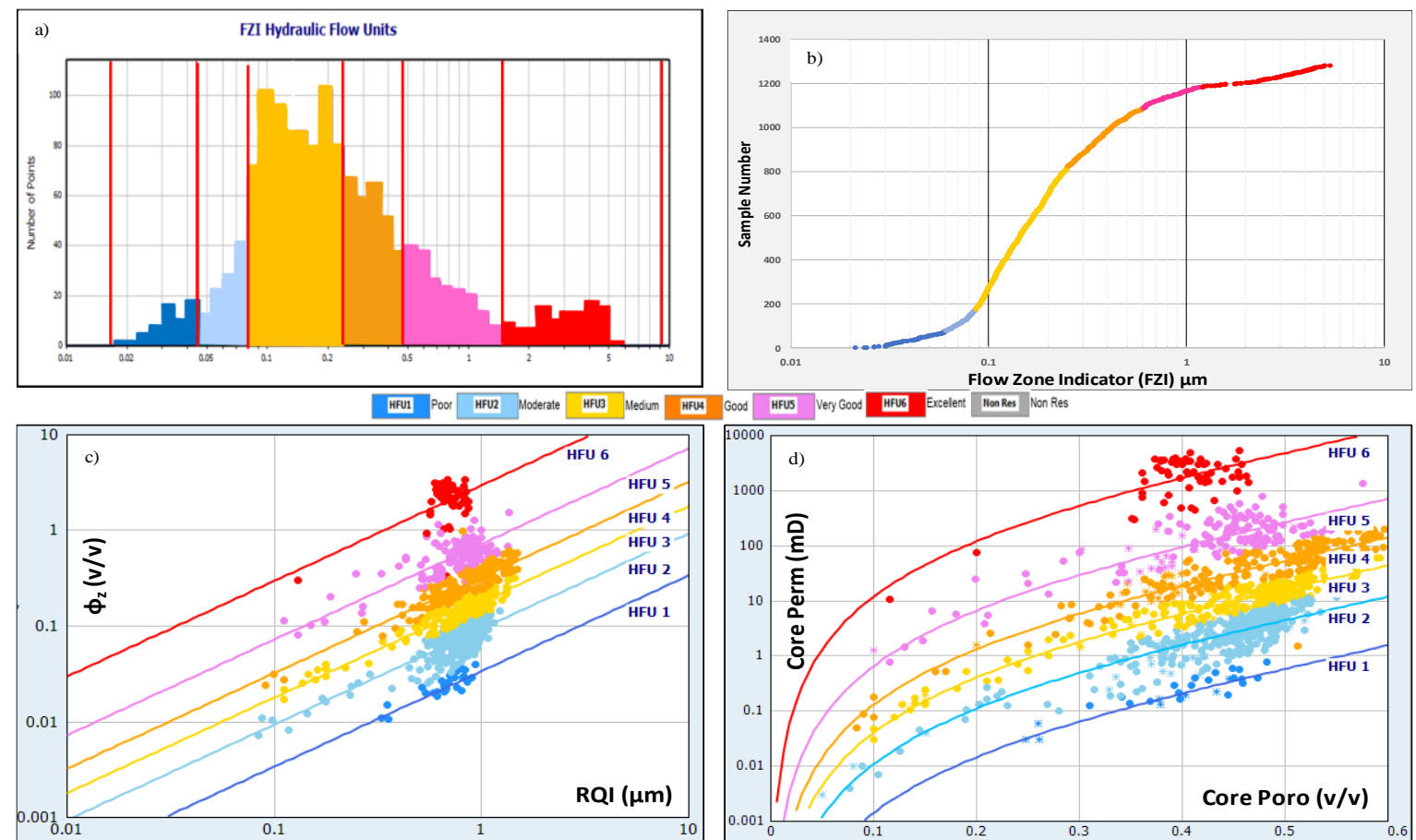

Figure 5. Hydraulic Flow Unit (HFU) analysis. a) Calculated Flow Zone Indicator (FZI) Histogram. b) Stratigraphic Lorenz Plot of FZI. c) Rock Quality Index (RQI) vs Normalized Porosity ( $\phi z)$ cross-plot d) Permeability Transform for each HFU.

\section{Water Saturation}

All Drill Steam Tests (DST's) result that were conducted above Lowest Known Gas (LKG) in seven wells (AX-1, AC-1, BF-1, BH1, DK-1, DA-1, and DA-4) only flew gas and no water. In BF-1 well, one of the three DST interval also conducted below LKG and the result is no flow. Therefore, no valid formation water analysis conducted in laboratory. The formation water salinity or formation water resistivity determined by using Pickett Plot method. Cementation (m) and saturation exponent (n) from special core analysis (rock electrical properties) data has been used for water saturation calculation [12]. The true resistivity (Rt) is taken from deepest resistivity reading measurements. Ideally, to get properly true resistivity, a resistivity modelling/ inversion work is required. The standard tornado charts are inadequate and strictly not applicable to the wireline logs. This is reasonable to the extent that we can argue that invasion effects are not noticeable in the deepest reading tools [13].

Water saturation from wireline log data was calculated using Indonesia Equation. This 
equation was used to accommodate the presence of volume of clay within the formation. The Indonesia Equation is written below:

$\frac{1}{\sqrt{R t}}=\left(\sqrt{\frac{\phi^{m}}{a * R w}}+\frac{V c l}{\sqrt{R c l}}\right) * S w^{\frac{n}{2}}$

\section{Elastic Properties (AI, SI, Vp/Vs, PR)}

Seismic wave propagation in the earth is affected not only by the physical state of the media (solid, liquid or gas) but also by other physical properties such as rock density, pore size, fluid content, depth of burial and differential pressure, etc. Physical properties of the earth can be measured in situ using acoustic sonic logging system [14]. In recent years there has been increased use of $\rho, \mathrm{Vp}$, and $\mathrm{Vs}$, in seismic exploration for estimation of porosity, lithology, saturating fluids in particular intervals and provide sufficient information to determine the elastic parameters of isotropic media. The possibly ambiguous interpretation of lithology and porosity from $\mathrm{Vp}$, $\mathrm{Vs}$, and $\mathrm{Vp} / \mathrm{Vs}$ in seismic exploration also applies to $\log$ analysis. However, because sonic logs are generally a part of standard logging programs, the interpretation of full waveform sonic logs should be made in the context of other logging information [15]. Although porosity is the most important factor to control sonic velocity, there are also various factors such as pore type, pore fluid incompressibility $(\lambda)$, shear modulus $(\mu)$, bulk modulus $(\mathrm{K})$ and saturation are control velocities in carbonate rocks.

The relationship that describes how the elastic moduli and density of the saturated rock relate to the corresponding $\mathrm{Vp}$, and $\mathrm{Vs}$ of a porous medium are given by below equation:

$$
V p=\sqrt{\frac{K+\frac{4}{3} \mu}{\rho}}=\sqrt{\frac{\lambda+2 \mu}{\rho}}
$$

As below equation, shear wave velocities are more strongly impacted by more porous and complicated fabric (rock matrix) and are very less effected by fluid type. The shear wave cannot propagate in fluids, as fluids do not behave elastically under shear deformation.

$$
V s=\sqrt{\frac{\mu}{\rho}}
$$

In the above equations, shear-wave velocity (Vs) depends only on the density $(\rho)$ of the saturated rock and the shear rigidity/modulus $(\mu)$, while the compressionalwave velocity $(\mathrm{Vp})$ depends on the bulk modulus $(\mathrm{K})$ of the saturated rock and on the shear rigidity $(\mu)$ and density $(\rho)$ of the saturated rock. Thus, we observe that $\mathrm{Vp}$ is dependent on two unknown dry-rock properties, while Vs depends only on one of them [2].

Based on $\rho, V p$ and Vs concept and as an input to geophysicist to cluster reservoir quality, the log base acoustic impedance and shear impedance can be calculated as below equations:

$$
\begin{aligned}
& A I=\rho * V p \\
& S I=\rho * V S
\end{aligned}
$$

Poisson's ratio $(\sigma)$ is the ratio between the lateral and longitudinal strains resulting from uniaxial stress applied to the rock. It is calculated from $\mathrm{Vp}$ and $\mathrm{Vs}$ using the following equation:

$$
\sigma=\frac{V p^{2}-2 V s^{2}}{2\left(V p^{2}-V s^{2}\right)}
$$

The Poisson's (or $\mathrm{Vp} / \mathrm{Vs}$ ) ratio is very sensitive to the existence of fluids. The $\mathrm{Vp} / \mathrm{Vs}$ (or the Poisson's) ratio is becoming a more useful parameter in the determination of rock properties. 


\section{RESULT AND DISCUSSION}

The reservoir porosity of Globigerina limestone is supported by matrix porosity and intergranular porosity. The reservoirs have total porosity up to $60 \%$ volume with permeability ranging from $1 \mathrm{mD}$ to over $1000 \mathrm{mD}$. From petrography analysis, major porosity types encountered in this reservoir are intra-particle porosity within foraminifera shell and inter-particle porosity (between foraminifera). Lime muds are the predominant material found in the matrix with only minor amounts of detrital clay observed. The best reservoir quality has less lime mud matrix filling and less clay association. Within this condition, the space between grains is still well preserved and only little diagenetic alteration occurs within the forams chambers.
Total eleven wells have complete quad combo conventional log responses such as gamma ray, resistivity, neutron, density, Vp and Vs (eight wells). After loading and checking of all wireline logs data, it was found that most of the wireline logs are aligned in depth so does not require any depth shift. The effects of tool position, tension, current fluctuation, cycle skipping, have been understood carefully. The corrected and conditioned wireline $\operatorname{logs}$ data must be confirmed through quality control methods. Petrophysical analysis conducted based on methodologies and data available as mentioned earlier. Final petrophysical results of eight representative wells that have Vs data are shown in Figure 6-13(a).
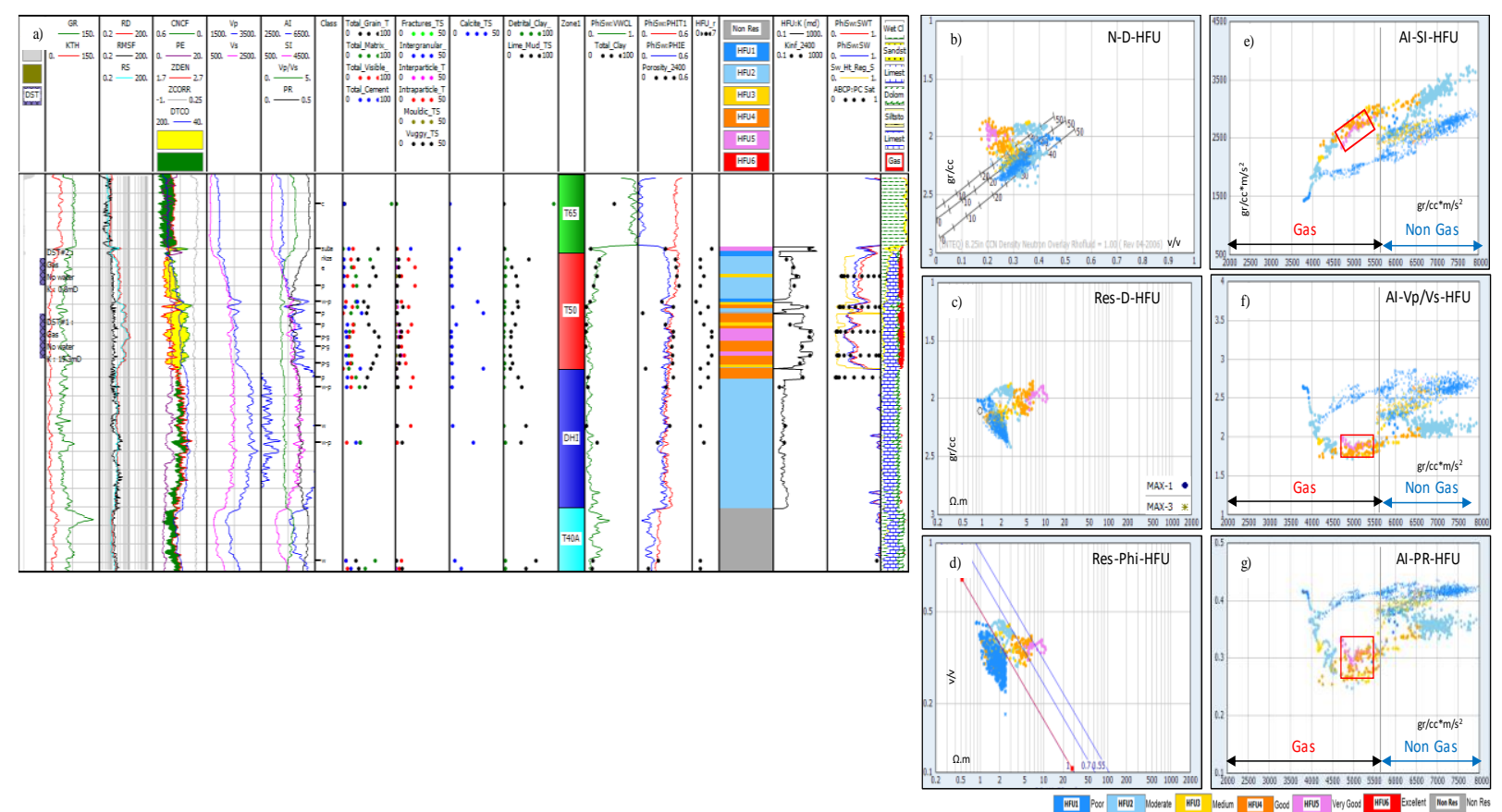

Figure 6. AX-1 Well Interpretation Result. a) Data Availability, Petrography Data, Petrophysical Result Validated with Core Data. b) Neutron-Density cross-plot. c) Resistivity-Density cross-plot. d) Resistivity-Porosity cross-plot. e) Acoustic Impedance-Shear Impedance cross-plot. f) Acoustic Impedance-Compressional/Shear Velocity Ratio cross-plot. g) Acoustic Impedance-Poisson's Ratio cross-plot. 

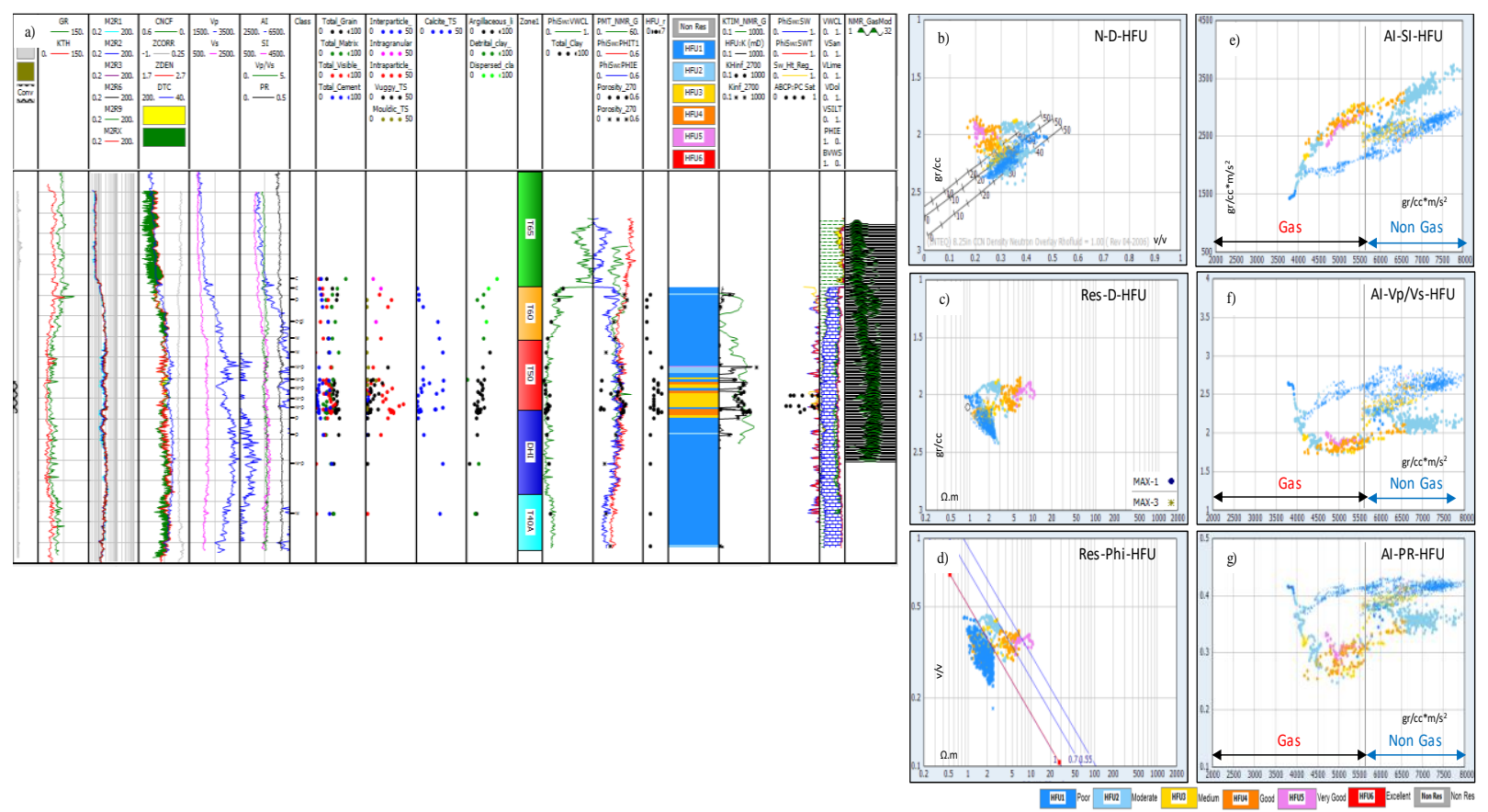

Figure 7. AX-3 Well Interpretation Result. a) Data Availability, Petrography Data, Petrophysical Result Validated with Core Data. b) Neutron-Density cross-plot. c) Resistivity-Density cross-plot. d) Resistivity-Porosity cross-plot. e) Acoustic Impedance-Shear Impedance cross-plot. f) Acoustic Impedance-Compressional/Shear Velocity Ratio cross-plot. g) Acoustic Impedance-Poisson's Ratio cross-plot.
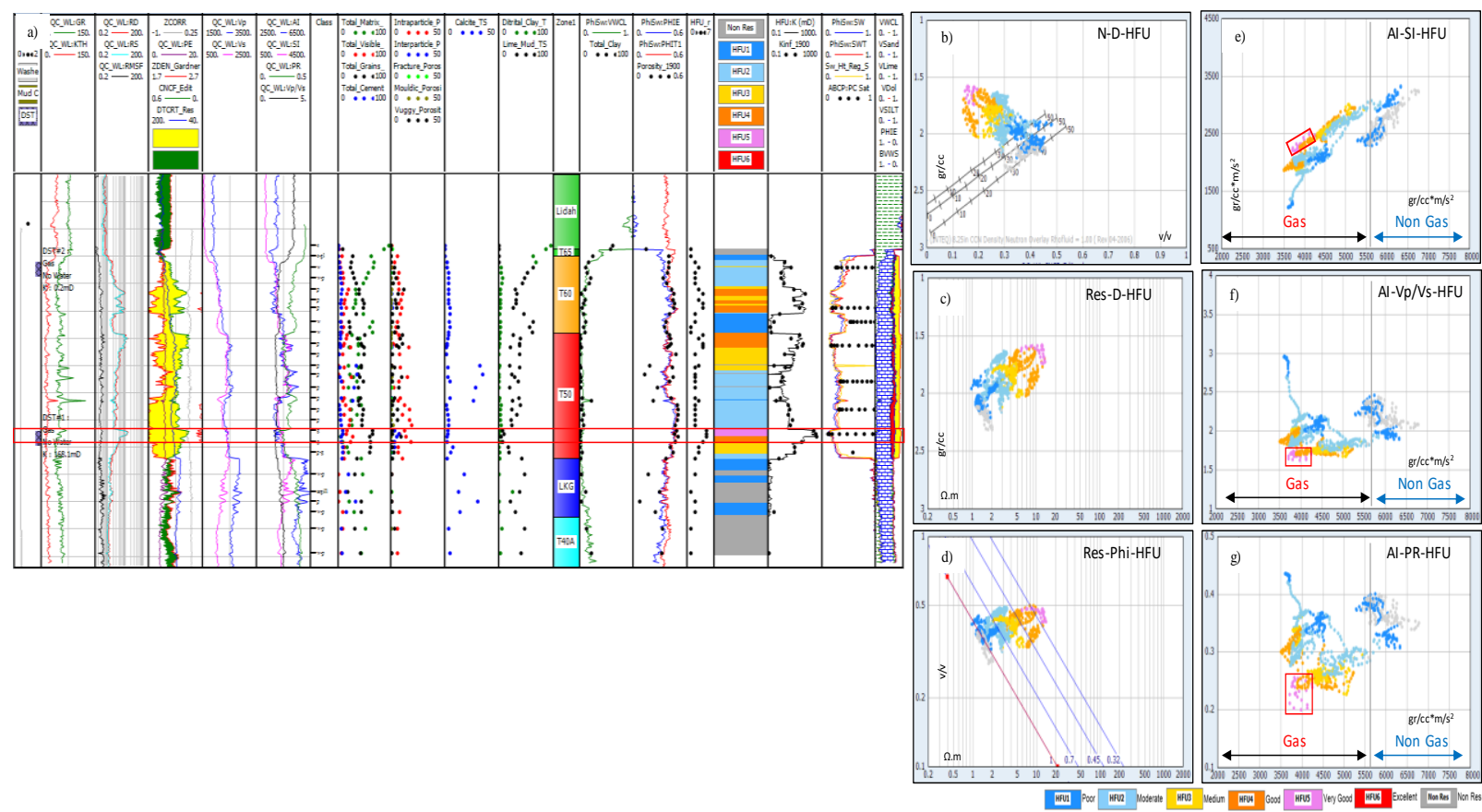

Figure 8. AC-1 Well Interpretation Result. a) Data Availability, Petrography Data, Petrophysical Result Validated with Core Data and Best Reservoir Quality in Red Box. b) Neutron-Density cross-plot. c) Resistivity-Density crossplot. d) Resistivity-Porosity cross-plot. e) Acoustic Impedance-Shear Impedance cross-plot. f) Acoustic ImpedanceCompressional/Shear Velocity Ratio cross-plot. g) Acoustic Impedance-Poisson's Ratio cross-plot. 

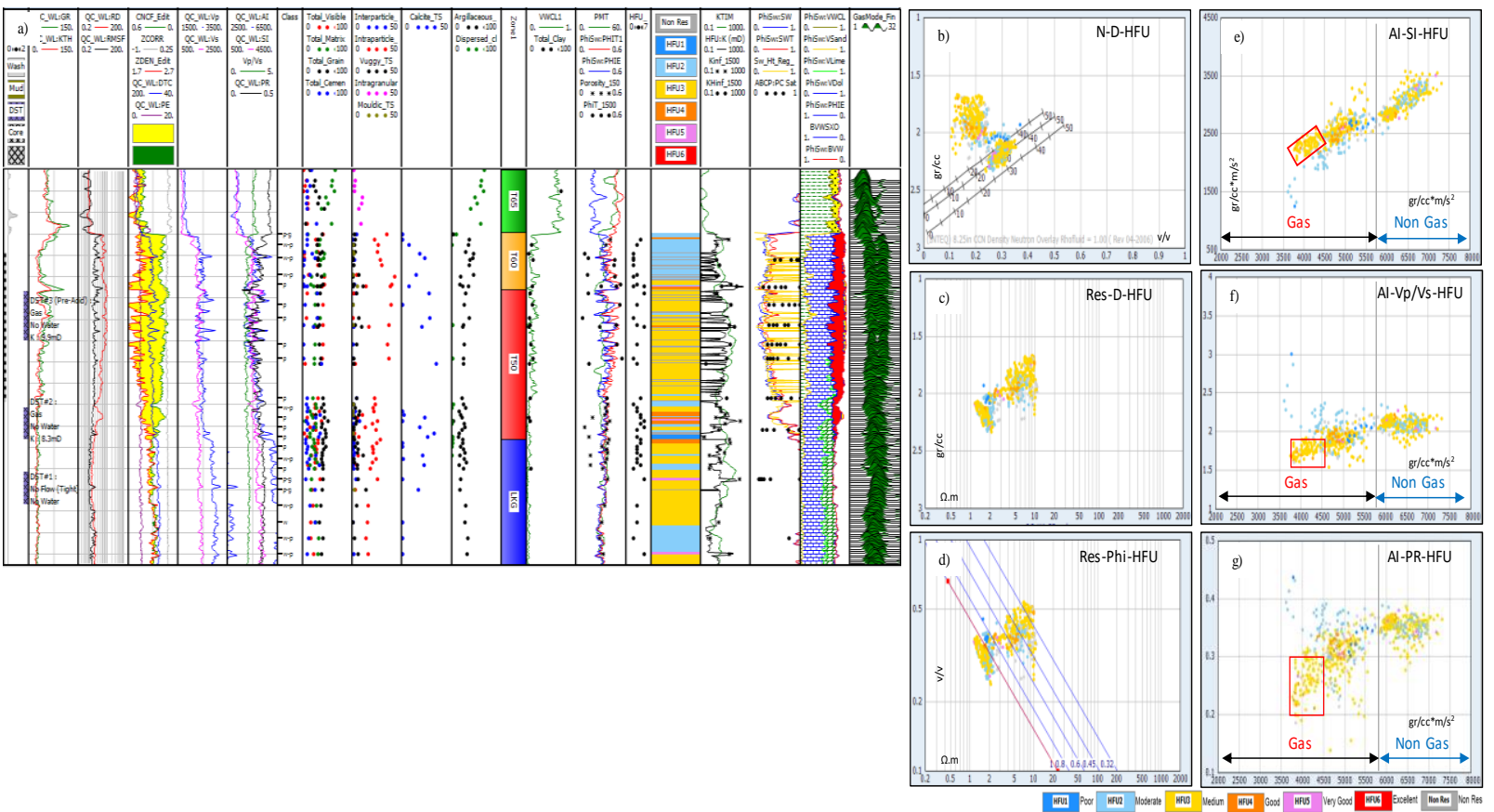

Figure 9. BF-1 Well Interpretation Result. a) Data Availability, Petrography Data, Petrophysical Result Validated with Core Data. b) Neutron-Density cross-plot. c) Resistivity-Density cross-plot. d) Resistivity-Porosity cross-plot. e) Acoustic Impedance-Shear Impedance cross-plot. f) Acoustic Impedance-Compressional/Shear Velocity Ratio cross-plot. g) Acoustic Impedance-Poisson's Ratio cross-plot.

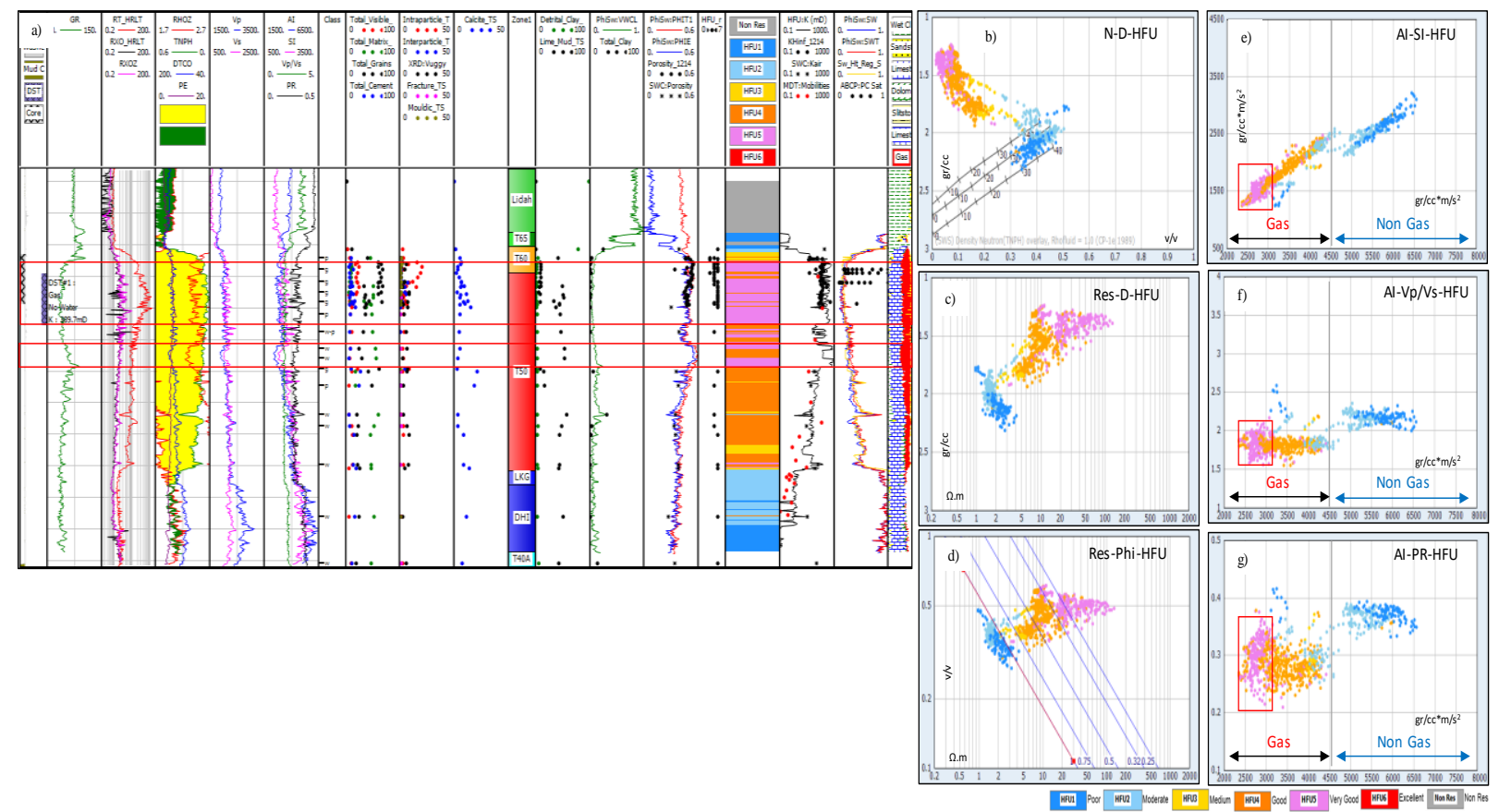

Figure 10. BH-1 Well Interpretation Result. a) Data Availability, Petrography Data, Petrophysical Result Validated with Core Data and Best Reservoir Quality in Red Box. b) Neutron-Density cross-plot. c) Resistivity-Density crossplot. d) Resistivity-Porosity cross-plot. e) Acoustic Impedance-Shear Impedance cross-plot. f) Acoustic ImpedanceCompressional/Shear Velocity Ratio cross-plot. g) Acoustic Impedance-Poisson’s Ratio cross-plot. 


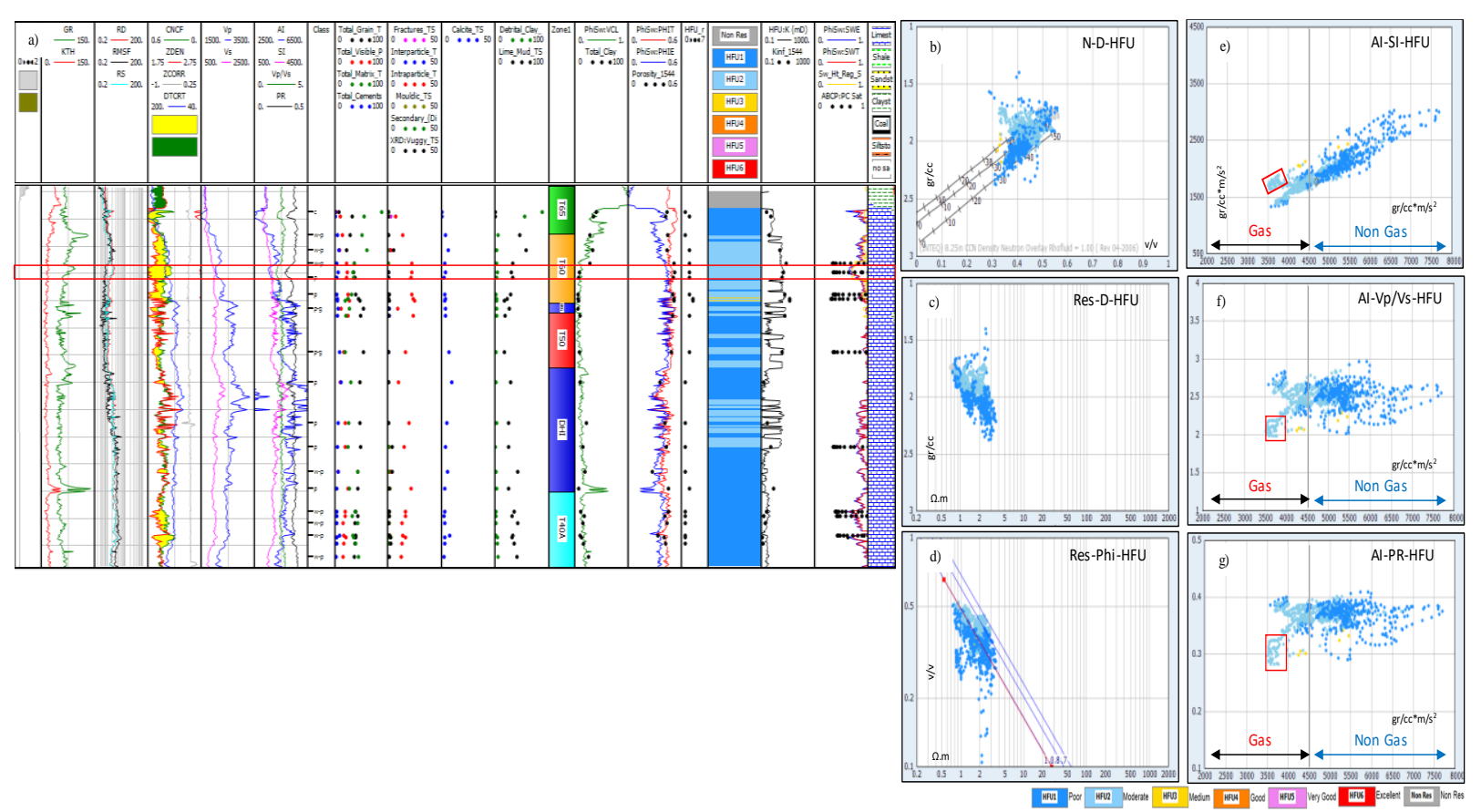

Figure 11. BJ-1 Well Interpretation Result. a) Data Availability, Petrography Data, Petrophysical Result Validated with Core Data and Best Reservoir Quality in Red Box. b) Neutron-Density cross-plot. c) Resistivity-Density crossplot. d) Resistivity-Porosity cross-plot. e) Acoustic Impedance-Shear Impedance cross-plot. f) Acoustic ImpedanceCompressional/Shear Velocity Ratio cross-plot. g) Acoustic Impedance-Poisson's Ratio cross-plot.
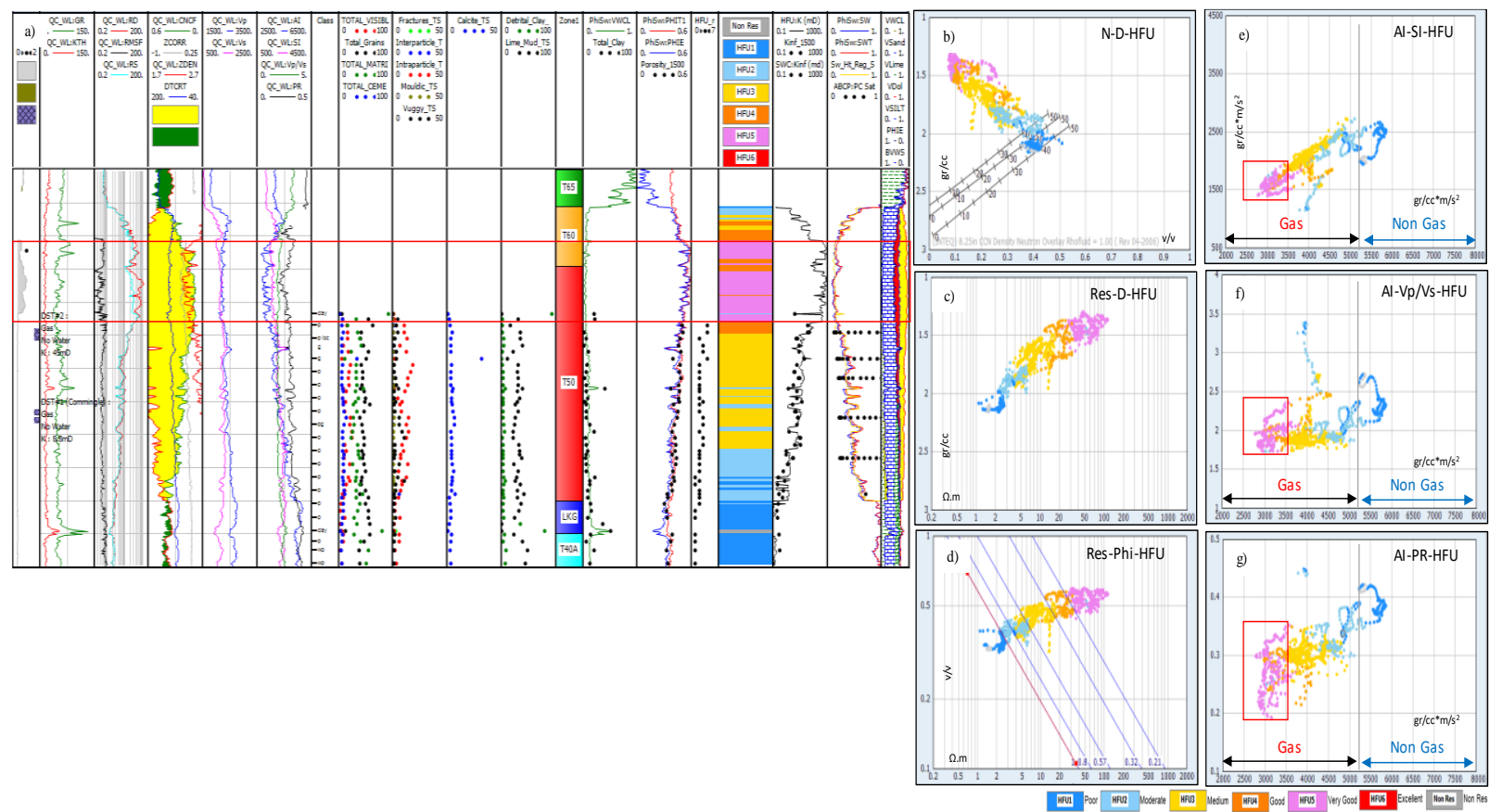

Figure 12. DK-1 Well Interpretation Result. a) Data Availability, Petrography Data, Petrophysical Result Validated with Core Data and Best Reservoir Quality in Red Box. b) Neutron-Density cross-plot. c) Resistivity-Density crossplot. d) Resistivity-Porosity cross-plot. e) Acoustic Impedance-Shear Impedance cross-plot. f) Acoustic ImpedanceCompressional/Shear Velocity Ratio cross-plot. g) Acoustic Impedance-Poisson's Ratio cross-plot. 


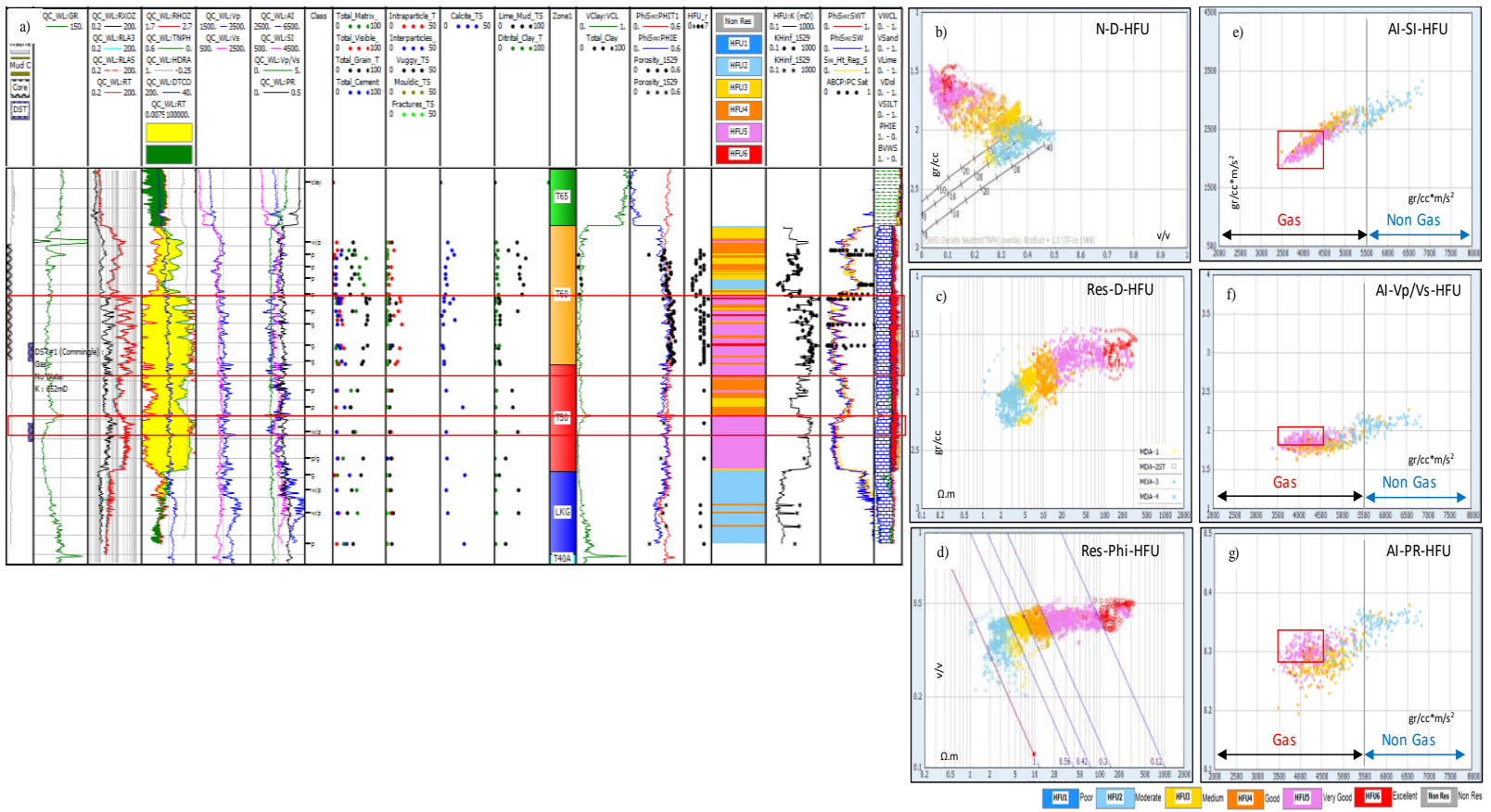

Figure 13. DA-4 Well Interpretation Result. a) Data Availability, Petrography Data, Petrophysical Result Validated with Core Data and Best Reservoir Quality in Red Box. b) Neutron-Density cross-plot. c) Resistivity-Density crossplot. d) Resistivity-Porosity cross-plot. e) Acoustic Impedance-Shear Impedance cross-plot. f) Acoustic ImpedanceCompressional/Shear Velocity Ratio cross-plot. g) Acoustic Impedance-Poisson's Ratio cross-plot.

The quality-controlled wireline logging curves are shown at tracks $1-6$ which consist of borehole condition, conventional core and DSTs interval; gamma ray; resistivity; compressional and shear velocity; acoustic impedance, shear impedance, compressionalshear velocity ratio, Poisson's ratio. The petrography data shown in track $7-11$, which consist of lithofacies; grain, matrix, visible porosity, cement; pore type; calcite cement; detrital clay, lime mud. Meanwhile, the interpretation result validated with core data, is shown in track 13-19 which consist of volume of clay validated with total clay from XRD; porosity $\log$ validated with core porosity; discrete HFU; continuous HFU; permeability $\log$ validated with core permeability; water saturation; fluid and lithology. The petrophysical results from eight discovery wells in Globigerina limestone reservoir obtain varying thickness in the range 120-450 ft with NtG 85 - 100\%. Globigerina limestone reservoirs are very clean with clay content less than $15 \%$. Because of major pore type came from intra granular porosity it makes porosity in reservoir very excellent within range $35-$ $50 \%$, meanwhile permeability varying from 8 $200 \mathrm{mD}$ and $\mathrm{Sw} 20-50 \%$.

Based on petrophysical and geological aspect, HFU classification in Globigerina limestone reservoir was carried out. The first step by applied porosity permeability cross plot from routine core analysis to classify each reservoir rock type. Each of rock type classification was integrated with the visual porosity and rock fabric character from microscopic studies. Mineralogical and textural characteristics of each flow unit determined from petrographic data (XRD, thin section photography and SEM). Capillary Pressure from air brines (ABCP) or High Pressure Mercury Injections (HPMI) also have been analyze to confirm each of the rock type. Capillary pressure curves behavior will represent the information from thin sections and SEM. This research resulted six flow units 
as reservoir rock with different quality from Poor (HFU1), Moderate (HFU2), Medium (HFU3), Good (HFU4), Very Good (HFU5) and Excellent (HFU6). The hydraulic flow unit quality is controlled by type of pore geometry as a function of mineralogy (abundance, morphology, and type), texture (packing, grain shape, grain size, sorting, pore throat and packing) and diagenesis. In order to predict HFU class in un-cored interval, electro-facies have been conducted through multi regression methodology with quad combo logs data as an input. As shown in figure $6-13(b-d)$, the most sensitive log to classify HFU class, came from resistivity, density and neutron log. Meanwhile gamma ray log is less sensitive due to mostly Globigerina limestone contain similar clay volume. This is corresponding with the concept where better reservoir quality will have lower water saturation that represent by high resistivity $\log$, and better porosity, represented by low neutron and low-density logs. The resulting HFU class have specific lithofacies, porosity/permeability cluster, mineralogy, pore geometries, pore throat, capillary pressure curve and fluid-flow characteristics. Each HFU class will have each permeability transform to predict continuous permeability log that will be validated by core permeability. The final result of continues HFU shown in figure 6-13 (a) in track 16 and the best HFU class in each well or field located in red box. This interval should be set as the optimize developments well target because the best rock quality contains less lime mud, minimum clay volume and water saturation, high porosity and permeability. With the best permeability as the target in the development wells, it will increase the flow rate.

Understanding the relationship between petrophysical result, HFU and elastic rock properties can be used further to predict the reservoir properties away from the well locations. Elastic rock properties derived from well logs are characterized in terms of HFU. One of the main objectives of this research is to understand and interpret elastic response for HFU. This can be achieved by conducting detailed cross plot analysis using different log attributes. It is not only helps to characterize identifiable HFU but also discern the rock quality and fluid effect based on different elastic properties. Several elastic rock properties cross plot with color coded by HFU form interval gas until non-gas fluid type are shown in figure $6-13(\mathrm{e}-\mathrm{g})$. As shown in figure $6-13(\mathrm{e}-\mathrm{g})$, AI has a powerful tool to separate gas and non-gas interval by using AI value $\sim 4,500-\sim 5,700\left(\mathrm{~g} / \mathrm{cc} * \mathrm{~m} / \mathrm{s}^{2}\right)$. Based on AI vs SI cross plot in figure $6-13(\mathrm{e})$, standalone AI parameter is less sensitive to distinguish HFU class but when it combines with SI, the clustered best HFU can be identified. In addition, the SI shows an overall decrease with higher HFU class, except in AX field. Base on AX-3 wells XRD data, it has higher amount of dolomite mineral. The dolomite mineral has higher density which make SI value higher. It can be said that SI has potential of being a good indicator for the influence of clay content, porosity, permeability and water saturation in term of HFU class. On figure 6-13 (f) which show AI vs $\mathrm{Vp} / \mathrm{Vs}$ ratio cross plot, $\mathrm{Vp} / \mathrm{Vs}$ ratios value between HFU classes, sometimes overlap each other especially in more heterogeneity reservoir quality. When $\mathrm{Vp} / \mathrm{Vs}$ ratio combine with AI it still can differentiate best HFU class. In addition, the $\mathrm{Vp} / \mathrm{Vs}$ ratio shows an overall decrease with higher HFU class. Based on figure $6-13(\mathrm{~g})$ which show AI vs Poisson's ratio cross plot, combinable elastic parameter can cluster the best HFU class. In addition, the Poisson's ratio shows an overall decrease with 
higher HFU class. These all because of most of $\mathrm{Vp}$ on the water-saturated are higher than the gas saturated rock, and most of Vs is less impacted by fluid type. In other words, combinable of all elastic rock properties can be used to localize the best HFU class which have high permeability. Therefore, when the best HFU class can be clustered using certain cut off of elastic parameter such AI, SI, Vp/Vs ratio and Poisson's ratio, the optimum developments well target and shorter production length can be obtained to achieve predetermined deliverability in the POD document. For sure, with shorter production length mean shorter development wells trajectory, shorter drilling rig time and will give more economic return.

\section{CONCLUSION}

A detailed Petrophysical analysis blended with elastic log response has been conducted. The petrophysical analysis have valid result for clay volume, porosity, permeability and water saturation, which have good match with core data. Permeability prediction has been conducted through HFU methodology. This study resulted six flow units as reservoir rock with different quality from Poor (HFU1), Moderate (HFU2), Medium (HFU3), Good (HFU4), Very Good (HFU5) and Excellent (HFU6). The HFU classification controlled by permeability, which affected by the existence of lime mud and little diagenetic alteration such as vugs, mouldic and heavily calcite cement. Each HFU class will have each permeability transform to predict continuous permeability log that will be validated by core permeability. As a link to understand the relationship among petrophysical, HFU and elastic rock properties which can be used further to predict the reservoir properties away from the well locations. Several cross plot of elastic rock properties derived from well logs have been used to optimize development well target. The AI could be used as powerful tool to separate gas and non-gas fluid type. The use of AI can be deeper by combination of SI, $\mathrm{Vp} / \mathrm{Vs}$ ratio and Poisson's ratio to localize which interval of reservoir in certain well or field that have the best HFU class. The best HFU class contains less lime mud, minimum clay volume and water saturation, high porosity, high permeability and vice versa. The best HFU class, will response specific range of AI, SI, Vp/Vs ratio and Poisson's ratio. With the best permeability as the target in the development wells, it will obtain optimum trajectory, shorter production length and achieve good deliverability.

\section{ACKNOWLEDGEMENT}

The author would like to thank HuskyCNOOC Madura Ltd., especially Subsurface Department for permission and support to publish data and analysis result. In addition, it would not have been possible without the permission from shareholder, SKK Migas and Dirjen Migas.

\section{REFERENCES}

1. Donaldson, E.; Tiab, D. Theory and Practice of Measuring Reservoir Rock and Fluid Transport Properties. In Petrophysics; Gulf Professional Publishing: Houston, Texas, 2003; p. 1008 ISBN 9780123838483.

2. Avseth, P.; Mukerji, T.; Mavko, G. Quantitative Seismic Interpretation. Applying Rock Physics to Reduce Interpretation Risk; Cambridge University Press: Cambridge, 2005; ISBN 0521816017.

3. Greenberg, M.L.; Castagna, J.P. Shear-wave Velocity Estimation in Porous Rocks: Theoretical Formulation, Preliminary Verification and Applications. Geophys. Prospect. 1992, 40, 195209.

4. Satyana, A.H.; Erwanto, E.; Prasetyadi, C. Rembang-Madura-Kangean-Sakala (RMKS) Fault Zone, East Java Basin: The Origin and Nature of A Geologic Border. In Proceedings of the Proc. IAGI, 33rd., Ann. Conv and Exh Bandung; 2004.

5. PT Patra Nusa Data Indonesia Basin Summaries; 
Jakarta, 2006.

6. Bransden, P.J.E.; Matthews, S.J. Structural and Stratigraphic Evolution of the East Java Sea, Indonesia. In Proceedings of the Proceedings of the Indonesian Petroleum Association, 21 Annual Convention; 1992; pp. 417-453.

7. Goodall, J. The Mundu and Selorejo Sequences: Stratigraphy, Paleoenvironments and Prospectivity; 2013.

8. Schlumberger Educational Services Log Interpretations Charts; Houston, Texas, 1977.

9. Asquith, G.B.; Gibson, C.R. Basic Well Log Analysis for Geologists; American Association of Petroleum Geologists: Tulsa, Oklahoma, 1982.

10. Lucia, F.J. Petrophysical Parameters Estimated from Visual Descriptions of Carbonate Rocks: A Field Classification of Carbonate Pore Space. $J$. Pet. Tech 1983, 35, 626-637.

11. Amaefule, J.O.; Altunbay, M.; Tiab, D.; Kersey, D.G.; Keelan, D.K. Enhanced Reservoir
Description: Using Core and Log Data to Identify Hydraulic (Flow) Units and Predict Permeability in Uncored Intervals/Wells. In Proceedings of the SPE Annual Technical Conference and Exhibition; Houston, 1993; pp. 1-16.

12. Pickett, G.R. Acoustic Character Log and Their Application in Formation Evaluation. J. Pet Tech 1963, 15, 659-667.

13. Archie, G.E. Classification of Carbonate Reservoir Rocks and Petrophysical Considerations. Am. Assoc. Pet. Geol. Bull. 1952, 36, 278-298.

14. Mavko, G.; Mukerji, T.; Dvorkin, J. The Rock Physics Handbook Tools for Seismic Analysis in Porous Media.; Cambridge University Press: Cambridge, 1998; ISBN 0521620686.

15. Biot, M.A. The Theory of Propagation of Elastic Waves in a Fluid Saturated Porous Solid. J. Acoust. Soc. Am. 1956, 28, 168-191, doi:10.1121/1.1908239. 